\title{
Article \\ 3D Printing of Hierarchically Porous Lattice Structures Based on Åkermanite Glass Microspheres and Reactive Silicone Binder
}

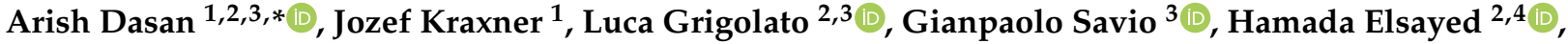 \\ Dušan Galusek 1,5 (D) and Enrico Bernardo $2, *$ (D) \\ 1 Centre for Functional and Surface-Functionalized Glass, Alexander Dubček University of Trenčín, \\ 91150 Trenčín, Slovakia; jozef.kraxner@tnuni.sk (J.K.); dusan.galusek@tnuni.sk (D.G.) \\ 2 Department of Industrial Engineering, Università degli Studi di Padova, 35131 Padova, Italy; \\ luca.grigolato@phd.unipd.it (L.G.); hamada.elsayed@unipd.it (H.E.) \\ 3 Department of Civil, Environmental and Architectural Engineering (ICEA), University of Padova, \\ 35131 Padova, Italy; gianpaolo.savio@unipd.it \\ 4 Refractories, Ceramics and Building Materials Department, National Research Centre, El Buhouth Str., \\ Cairo 12622, Egypt \\ 5 Joint Glass Centre of the IIC SAS, TnUAD, and FChFT STU, FunGlass, Alexander Dubček University of \\ Trenčín, 91150 Trenčín, Slovakia \\ * Correspondence: arish.dasan@tnuni.sk or arishd82@gmail.com (A.D.); enrico.bernardo@unipd.it (E.B.)
}

Citation: Dasan, A.; Kraxner, J.; Grigolato, L.; Savio, G.; Elsayed, H.;

Galusek, D.; Bernardo, E. 3D Printing of Hierarchically Porous Lattice Structures Based on Åkermanite Glass Microspheres and Reactive Silicone Binder. J. Funct. Biomater. 2022, 13, 8. https://doi.org/ $10.3390 /$ jfb13010008

Academic Editors: Anişoara Cîmpean, Florin Miculescu and Ibrahim Tarik Ozbolat

Received: 13 December 2021

Accepted: 11 January 2022

Published: 13 January 2022

Publisher's Note: MDPI stays neutral with regard to jurisdictional claims in published maps and institutional affiliations.

Copyright: (C) 2022 by the authors. Licensee MDPI, Basel, Switzerland. This article is an open access article distributed under the terms and conditions of the Creative Commons Attribution (CC BY) license (https:// creativecommons.org/licenses/by/ $4.0 /)$.

\begin{abstract}
The present study illustrates the manufacturing method of hierarchically porous 3D scaffolds based on åkermanite as a promising bioceramic for stereolithography. The macroporosity was designed by implementing 3D models corresponding to different lattice structures (cubic, diamond, Kelvin, and Kagome). To obtain micro-scale porosity, flame synthesized glass microbeads with $10 \mathrm{wt} \%$ of silicone resins were utilized to fabricate green scaffolds, later converted into targeted bioceramic phase by firing at $1100{ }^{\circ} \mathrm{C}$ in air. No chemical reaction between the glass microspheres, crystallizing into åkermanite, and silica deriving from silicone oxidation was observed upon heat treatment. Silica acted as a binder between the adjacent microspheres, enhancing the creation of microporosity, as documented by XRD, and SEM coupled with EDX analysis. The formation of 'spongy' struts was confirmed by infiltration with Rhodamine B solution. The compressive strength of the sintered porous scaffolds was up to $0.7 \mathrm{MPa}$ with the porosity of $68-84 \%$.
\end{abstract}

Keywords: bioceramics; åkermanite; glass microspheres; additive manufacturing; silicones

\section{Introduction}

From a synthetic bone graft engineering perspective, the integration of multi-scale (macro-sized combined with micro- and nano-sized) porosity in 3D scaffolds is highly attractive [1,2]. Interconnected macropore networks $(>100 \mu \mathrm{m})$ are essential for bone ingrowth, bone regeneration, and nutrient transport/waste evacuation, whereas micro- and nano-porosity aids cells adhesion and cell evolution [3]. At the same time, the mechanical properties of the grafted scaffolds are often compromised as the result of increased porosity. Notably, for load-bearing sites, a fine balance of mechanical support during degradation is important since the load should be slowly transferred to the regenerating bone tissue. Therefore, fine-tuning of these properties to achieve materials exhibiting a high strength-todensity ratio-with an optimal microstructure-is imperative, but still an open issue in the field of bone tissue engineering (BTE).

Additive manufacturing (AM) technologies, in general, have a great potential for the obtainment of advanced bioceramic scaffolds featuring complex shapes. Ideally, the structure of macroporous scaffolds can be easily tailored using computer-aided design (CAD), subsequently transferred to several AM machines [4,5]. Recent efforts have been devoted to the development of micro/nanoporous structures in the same scaffolds through 
processing routes $[6,7]$. The simultaneous control of macro-porosity and micro/nanoporosity, however, remains an open issue.

The present investigation refers to åkermanite $\left(\mathrm{Ca}_{2} \mathrm{MgSi}_{2} \mathrm{O}_{7}\right.$, i.e., $\left.2 \mathrm{CaO} \cdot \mathrm{MgO} \cdot 2 \mathrm{SiO}_{2}\right)$, one of the most interesting bioceramic systems studied in recent years. The use of bioceramics as bone scaffolds not only supports and stimulates new bone ingrowth but also provides mechanical support during tissue regeneration through mechano-transduction [8]. In the case of åkermanite, it has been found that the release of silicon, calcium, and magnesium ions as degradation by-products, with specific rates, play a vital role in the immune regulation and thereby fosters in situ tissue regeneration [9-12]. Again, an open issue consists of the coupling of advantages of åkermanite with the favourable topological features of hierarchically porous scaffolds mentioned above.

In our previous investigation, spherical glass particles with exact åkermanite stoichiometry were utilized to manufacture 3D scaffolds using the stereolithography AM technique [13]. Embedded into commercial acrylate precursors, microbeads allow photocurable slurries with much enhanced solid content, compared to irregular particles, with advantages in the integrity of scaffolds upon burn-out of the organic additive and densification upon viscous flow sintering. A remarkable struts densification, although favourable for the mechanical properties, is not desirable in the perspective of hierarchically porous scaffolds. Some limitations of viscous flow densification could come from the sudden increase of viscosity upon sintering, related to the crystallization of microbeads. This generally implies a need for careful control of heat treatment conditions. The present paper aims at the development of an alternative strategy, consisting of the exploration of silicone resin as a binder additive that yields upon heating a $\mathrm{SiO}_{2}$-rich phase. This phase 'freezes' the densification of glass microbeads that crystallize into the desired åkermanite phase.

\section{Materials and Methods}

Glass microbeads with åkermanite stoichiometric composition $\left(\mathrm{Ca}_{2} \mathrm{MgSi}_{2} \mathrm{O}_{7}\right.$, i.e., $\left.2 \mathrm{CaO} \cdot \mathrm{MgO} \cdot 2 \mathrm{SiO}_{2}\right)$, manufactured by a flame synthesis technique, were used as the feedstock material. The detailed synthesis procedure was reported in our previous investigation [13]. High-quality liquid acrylate monomer (Prusa Resin-Tough, Original Prusa SL-1, Prusa Research a.s., Prague, Czech Republic) was used as UV photosensitive (405 nm) resin, supporting stereolithography 3D printing. A non-photocurable liquid silicone resin (H62C, Wacker-Chemie $\mathrm{GmbH}$, Munich, Germany) was used as a preceramic polymer (ceramic yield $=58 \%$ ) binder additive. Photocurable suspensions comprised microbeads $(65 \mathrm{wt} \%)$ in photosensitive precursor with silicone resin added as $10 \mathrm{wt} \%$ of the total slurry weight.

Four different lattice-based models (Cubic; number of cells in $\mathrm{x}, \mathrm{y}$ and $\mathrm{z}$ direction: $3 \times 3 \times 3$, cell dimension: $3 \mathrm{~mm} \times 3 \mathrm{~mm} \times 3 \mathrm{~mm}$, strut thickness: $1 \mathrm{~mm}$, theoretical relative density (TRD): $65 \%$, Diamond; $4 \mathrm{~mm} \times 4 \mathrm{~mm} \times 4 \mathrm{~mm}, 7 \mathrm{~mm} \times 7 \mathrm{~mm} \times 7 \mathrm{~mm}$, $0.8 \mathrm{~mm}, 85 \%$, Kelvin; $4 \mathrm{~mm} \times 4 \mathrm{~mm} \times 4 \mathrm{~mm}, 12.7 \mathrm{~mm} \times 12.7 \mathrm{~mm} \times 12.7 \mathrm{~mm}, 1.6 \mathrm{~mm}$, $92 \%$, and Kagome; $4 \mathrm{~mm} \times 4 \mathrm{~mm} \times 4 \mathrm{~mm}, 8 \mathrm{~mm} \times 8 \mathrm{~mm} \times 8 \mathrm{~mm}, 1.2 \mathrm{~mm}, 72 \%$ ) were designed, using the Rhinoceros 7 software, as shown in Figure 1, and used as a reference for the adopted masked stereolithography desktop printer (Original Prusa SL-1, Prusa Research s.r.o, Prague, Czech Republic), operating in the visible light range (between 400 and $500 \mathrm{~nm}$ ). The adopted layer thickness was $50 \mu \mathrm{m}$, with an exposition lasting $7 \mathrm{~s}$ for each layer. The green scaffolds were subjected to debinding at $600^{\circ} \mathrm{C}$ for $3 \mathrm{~h}$, with a heating rate of $0.2{ }^{\circ} \mathrm{C} / \mathrm{min}$, followed by sintering at $1100{ }^{\circ} \mathrm{C}$, both in the air and flowing nitrogen, for $1 \mathrm{~h}$ (heating rate $5^{\circ} \mathrm{C} / \mathrm{min}$ ). 
(a)

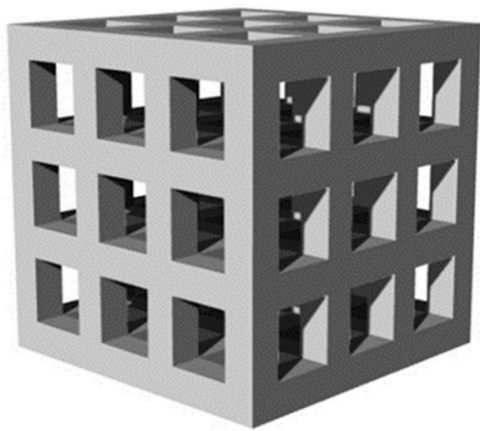

(c)

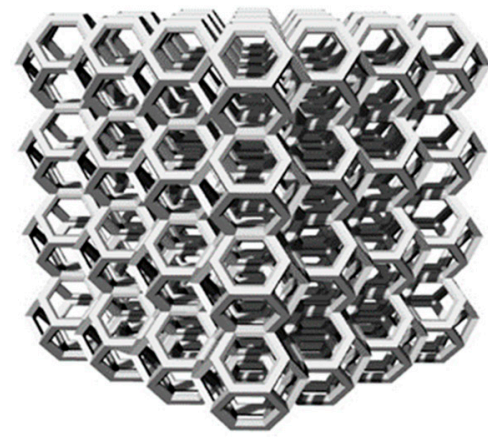

(b)

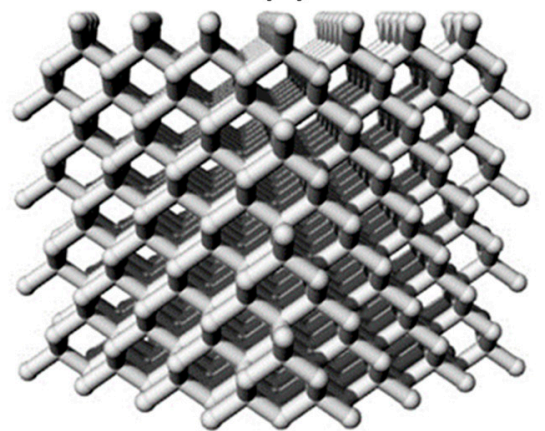

(d)

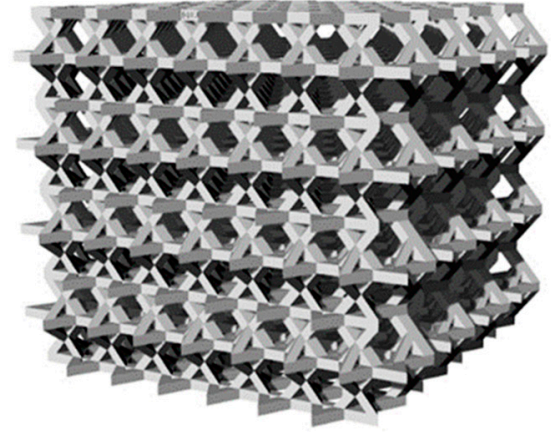

Figure 1. Lattice-based cellular assemblies adopted for MSLA scaffolds: (a) cubic; (b) diamond; (c) Kelvin; and (d) Kagome.

The mineralogical phases were identified using an X-ray powder diffractometer (Panalytical Empyrean, Malvern Panalytical, Eindhoven, The Netherlands) using $\mathrm{Cu}$ anode $\left(K \alpha_{1}=1.5406 \AA\right.$ and $\left.K \alpha_{1}=1.5444 \AA\right)$ equipped with a nickel $K \beta$ filter. The diffraction data were evaluated using the software High Score Plus (v.3.0.4, Malvern Panalytical, Eindhoven, The Netherlands) supported by Crystallographic Open Database (COD_2013).

Microstructural analysis on the sintered scaffolds was conducted by optical stereomicroscopy (AxioCamERc 5s Microscope Camera, Carl Zeiss Microscopy, Thornwood, New York, NY, USA) and scanning electron microscopy (SEM, JEOL 7600 F, JEOL Ltd., Tokyo, Japan) using an accelerating voltage of $20 \mathrm{kV}$. The semiquantitative chemical analysis was carried out using an Energy Dispersion X-Ray Spectrometer (EDS, Oxford Instruments, Oxford, UK) within Aztec systems (Oxford Instruments, Oxford, UK) with the ZAF (Z-atomic number, A-X-ray absorption, F-X-ray fluorescence) matrix correction method.

The geometrical density of the sinter-crystalized scaffolds was measured using a digital caliper and by weighting with an analytical balance. The apparent and true densities of the printed parts were measured by He pycnometry (Micromeritics AccuPyc 1330, Norcross, GA, USA), on bulk (3D printed scaffolds) and powdered samples, respectively. Total, open, and closed porosities were calculated according to the measured density values. Finally, the sintered scaffolds were impregnated with Rhodamine B solution (0.5\% in 2-Propanol) to visualize the open porosity in the struts. The compressive strength of the fired scaffolds was measured using a universal testing machine (Quasar 25, Galdabini S.p.a., Cardano al Campo, Italy), operating with a cross-head speed of $0.5 \mathrm{~mm} / \mathrm{min}$.

\section{Results and Discussion}

Flame synthesis is particularly useful for the production of glass microspheres with controllable size $(25-63 \mu \mathrm{m})$, especially in systems featuring a high crystallization rate such as åkermanite [13]. As mentioned previously, a primary aim was avoiding intensive viscous flow densification with shape loss, so that the hierarchical porosity could be determined simply by the packing of spheres. The binding of particles, after firing, had to be provided by the ceramic residue of the silicone additive. Silicones can be considered as reactive 
binders, since (i) they can be mixed with organic solvents and photocurable resin; (ii) they provide additional binding action, for un-sintered particles, at the burn-out of the organic compounds (at 500-600 ${ }^{\circ} \mathrm{C}$ ), before high-temperature sintering; (iii) they contribute to the composition of the final ceramic [14,15]. Figure 2 confirms the feasibility of the fabrication of complex-shaped objects according to this approach.
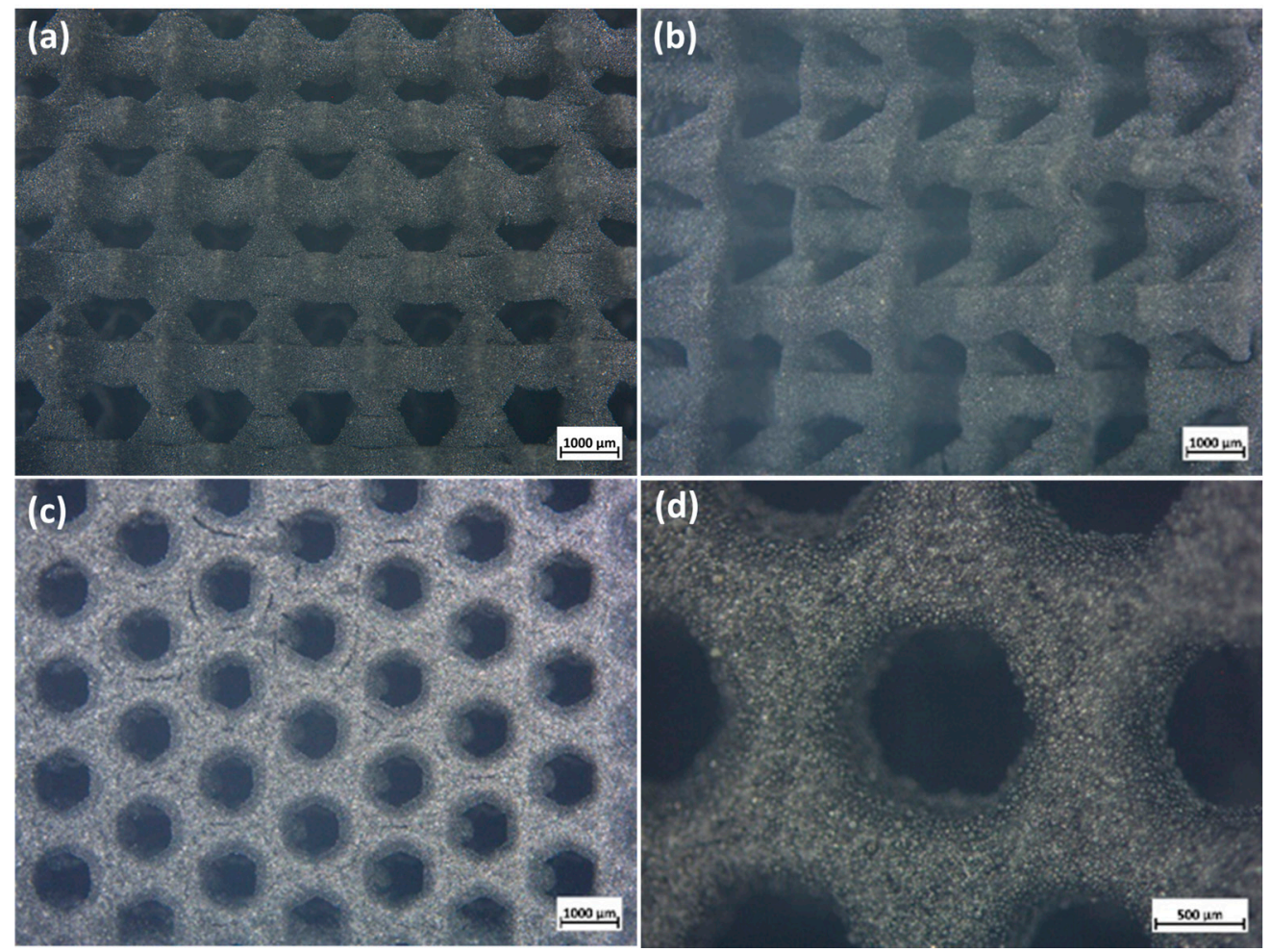

Figure 2. Optical images of selected 3D scaffolds (Kagome model); fired in nitrogen (a) front; (b) side; (c,d) top view.

The XRD pattern of as-synthesized microbeads, scaffolds fired at $1100{ }^{\circ} \mathrm{C} / 1 \mathrm{~h}$ without (for comparison) and with silicone resins are presented in Figure 3. While the starting material was XRD amorphous (Figure 3a), the presence of åkermanite (PDF \#83-1815), as the dominant crystalline phase (Figure $3 b-d$ ) in fired samples was confirmed. Additional diffraction maxima were attributed to traces of merwinite [ $\mathrm{Ca}_{3} \mathrm{MgSi}_{2} \mathrm{O}_{8}, \mathrm{PDF} \# 89-2432$ ] and diopside [ $\mathrm{CaMgSi}_{2} \mathrm{O}_{6}$, PDF \#75-1092] also known as excellent biomaterials [16].

Scaffolds fabricated using $\mathrm{H} 62 \mathrm{C}$ silicone as binder additive, fired in the air, showed an additional peak centered at $2 \theta=22^{\circ}$ attributed to the presence of silicone-derived crystalline $\mathrm{SiO}_{2}$ [cristobalite, PDF \#82-1014] (Figure 3c) [17]. Unlike in previous investigations on silicone/glass interaction [14,15], the resin and the glass microbeads did not chemically interact, and evolved independently. Additional evidence comes from the SEM images (Figure 4), showing that silica could act as a binder between adjacent microspheres. In particular, the high packing induced by using spherical particles is evident from Figure $4 \mathrm{a}$. Silicone-derived material, as shown in Figure $4 \mathrm{~b}$, could at the same time bind the particles and prevent their coalescence, leaving a system of interconnected channels, visible also in Figure 5. The chemical composition of selected areas determined by energy-dispersive spectroscopy (EDS, Figure 5) reveals the distinction between microbeads (involving Ca and $\mathrm{Mg}$ ) and silicone-derived binding phase (Ca- and $\mathrm{Mg}$-free). 


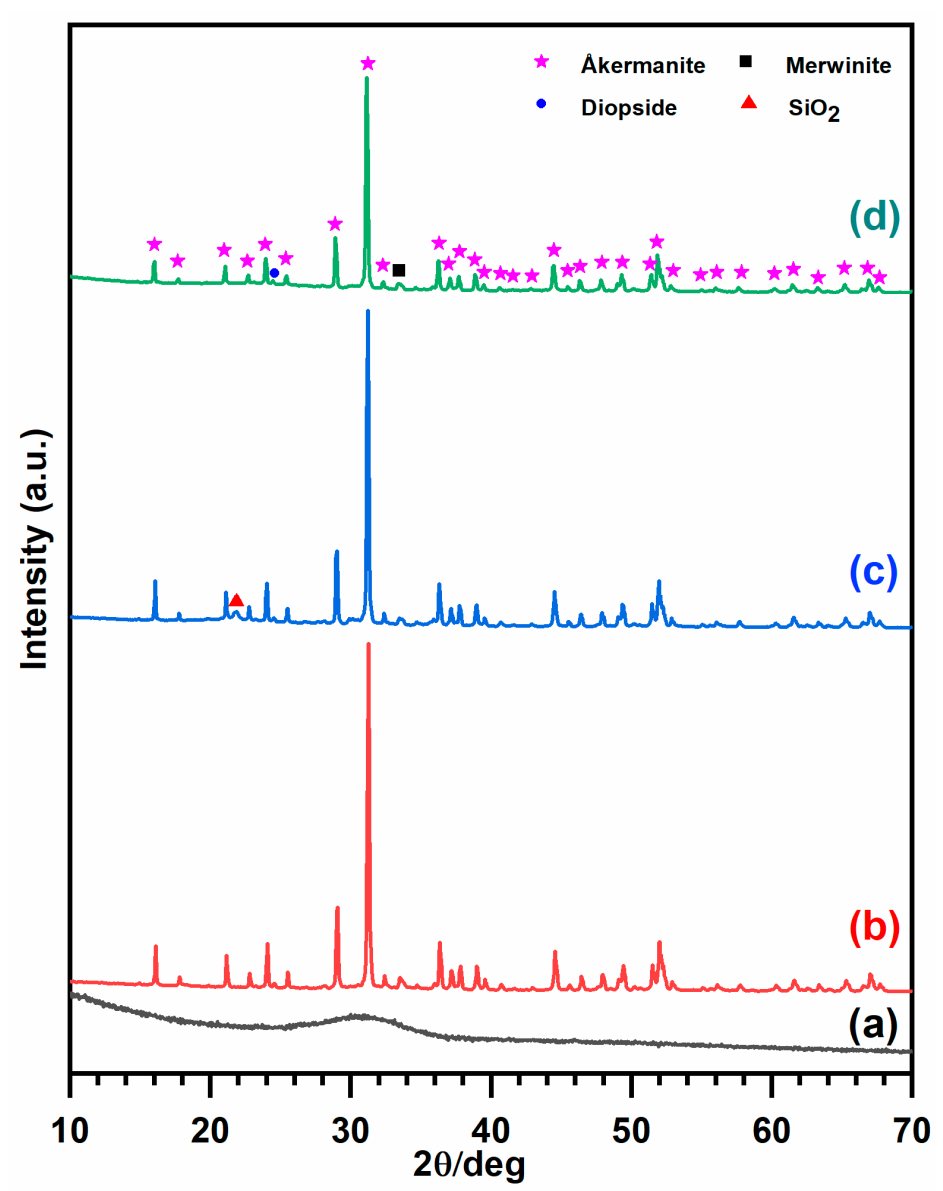

Figure 3. XRD patterns of (a) as-synthesized microspheres; (b) sintered scaffolds without silicone binder at $1100{ }^{\circ} \mathrm{C}$ in the air; (c) sintered scaffolds with silicone binder at $1100{ }^{\circ} \mathrm{C}$ in air; and (d) nitrogen.

In contrast, the scaffolds fired in flowing nitrogen (Figure 6a) did not show any cristobalite peak (Figure 3d). Again, crystallization only occurred within the microspheres while the silicone-derived binding phase remained amorphous, creating a silicon oxycarbide (SiOC) matrix. As documented by Figure $6 b-d$, the spherical particles were embedded in the SiOC matrix but not completely covered (due to the low content of SiOC).

The fact that åkermanite crystallization was not affected by the silicone conversion into cristobalite or amorphous $\mathrm{SiOC}$ matrix is promising. The new systems may be seen as analogous to previously investigated $\mathrm{CaCO}_{3}$-silicone systems [18,19]. Unreacted, bioactive calcite could be embedded in inert silica or SiOC phase, having favorable biological response.

The poor sintering of glass microbeads, as a result of the presence of silica/SiOC intermediate layers, was expected to penalize the compressive strength, but specific topologies and firing conditions could provide certain compensation. Different cellular structures imply different stress distributions; compressive loading, in particular, corresponds to the bending or stretching of structural elements (depending on the specific model) [20]. 

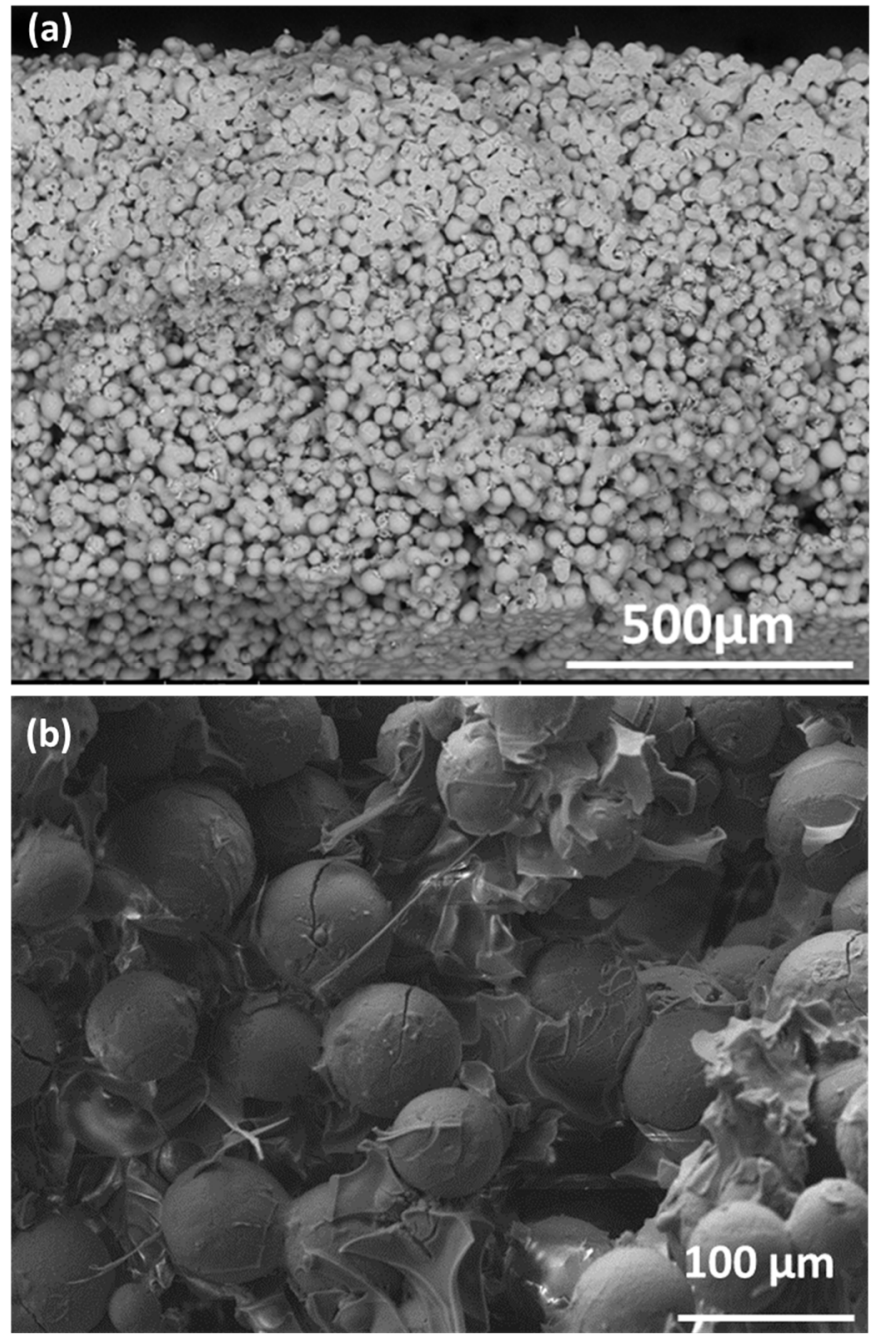

Figure 4. Low (a) and high (b) magnification SEM images of samples fired at $1100{ }^{\circ} \mathrm{C}$ in air.
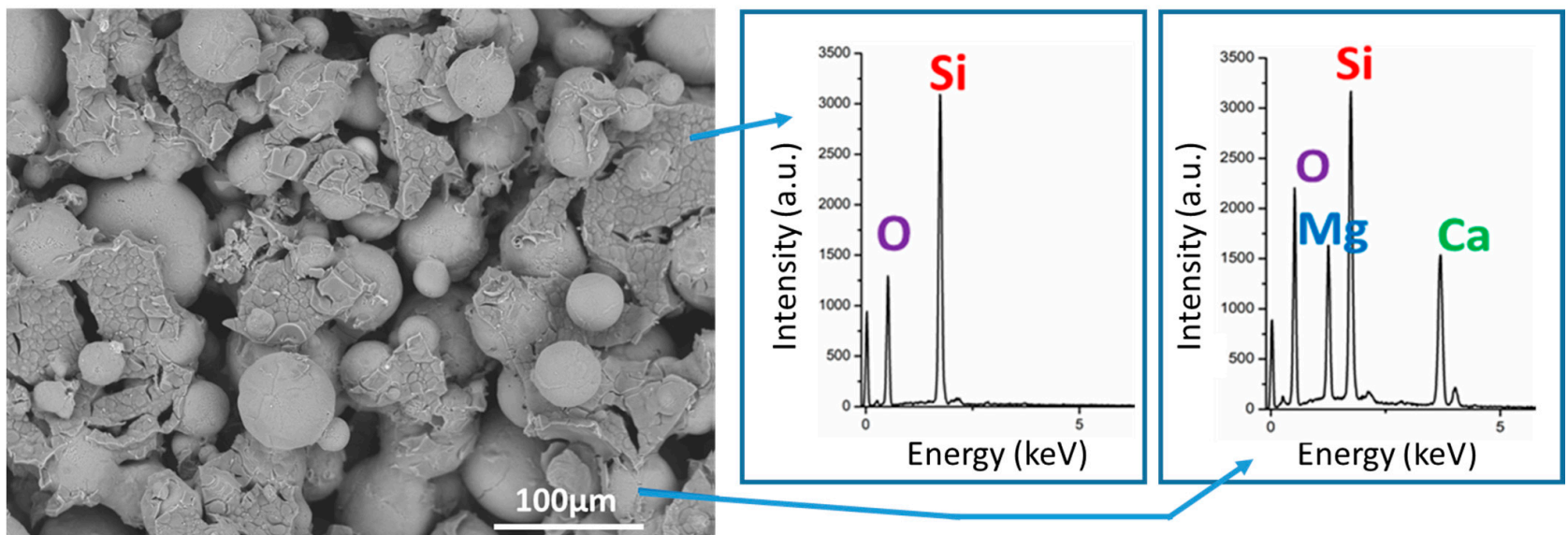

Figure 5. Higher magnification SEM micrograph and EDX spectra were recorded in the selected area of the scaffolds fired at $1100{ }^{\circ} \mathrm{C}$ in air. 

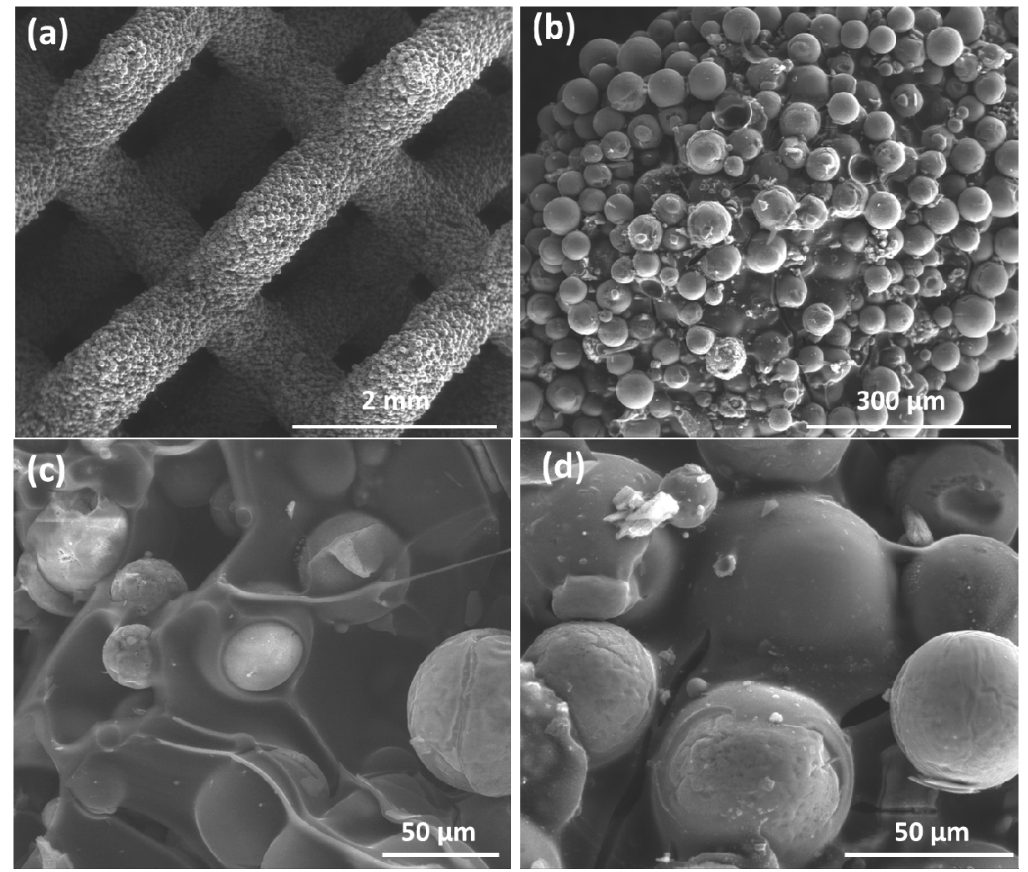

Figure 6. SEM images of samples fired at $1100{ }^{\circ} \mathrm{C}$ in nitrogen: (a) diamond cell structure; (b) packing of microbeads in a strut; (c-d) high magnification detail revealing the inclusion of microbeads in SiOC matrix.

The compressive strength measurements together with the porosity determinations are summarized in Table 1. The samples with the highest porosity showed a very low mechanical strength; some samples could be crushed by simple hand pressure, especially in the case of the Kelvin model, and are not considered in Table 1. However, changes in the design determined a remarkable increase of compressive strength, from 0.07 to $0.75 \mathrm{MPa}$. Such values are not directly comparable, since the total porosity, almost completely open, varied substantially (i.e., from 68 to $84 \%$ ). A more reliable comparison comes from the calculation of the bending strength of the solid phase. According to the studies conducted by Gibson and Ashby [20], a highly porous ceramic lattice or sponge has a compressive strength ruled by:

$$
\sigma_{\mathrm{c}} \sim 0.2 \cdot \sigma_{\text {bend }} \cdot\left(\rho_{\text {rel }}\right)^{1.5}
$$

where $\rho_{\text {rel }}$ is the relative density $\left(\rho_{\text {rel }}=1-\mathrm{P} / 100\right)$ and $\sigma_{\text {bend }}$ is the bending strength of the solid phase positioned in the struts. Reversing the equation, $\sigma_{\text {bend }}{ }^{*}$ values could be obtained from experimentally determined values of compressive strength and porosity (see Table 1), which could be interpreted as the bending strength of the solid of a Gibson and Ashby lattice with the same compressive strength and porosity. The substantial differences (from 6 to $28 \mathrm{MPa}$ ) confirm the progress achieved through topological changes. The $\sigma_{\text {bend }}{ }^{*}$ values remain well below the bending strength of dense glass-ceramics ( $>100 \mathrm{MPa})$ [21], but the results from the Kagome structure are reputed as quite adequate for the application (at least in not-severely loaded implants). This can be easily understood from Figure 7, showing a compressive strength/density chart for biological materials (image and data from a commercial materials selection software package [22]). Any material is conventionally displayed as an ellipsis, with height and width defined according to minimum and maximum values of compressive strength and density; the statistical variations are actually better represented by a box. Especially SiOC-boned Kagome scaffolds approach m values of the femur trabecular bone. 
Table 1. Density and strength determinations.

\begin{tabular}{|c|c|c|c|c|c|}
\hline $\begin{array}{l}\text { 3D Lattice } \\
\text { Structures }\end{array}$ & Atm & $\begin{array}{c}\text { Geometrical } \\
\text { Density, } \rho \\
\left(\mathrm{g} / \mathrm{cm}^{3}\right)\end{array}$ & $\begin{array}{c}\text { Total Porosity, P } \\
\quad(\text { vol \%) } \\
{\left[\rho_{\text {rel }}=1-P / 100\right]}\end{array}$ & $\begin{array}{l}\text { Open } \\
\text { Porosity } \\
\text { (vol \%) }\end{array}$ & $\begin{array}{l}\text { Compressive } \\
\text { Strength, } \sigma_{\mathrm{c}} \\
(\mathrm{MPa}) \\
{\left[\sigma_{\text {bend }}{ }^{*}(\mathrm{MPa})\right]}\end{array}$ \\
\hline \multirow{2}{*}{ Diamond } & air & $0.46 \pm 0.01$ & $\begin{array}{c}83.6 \pm 0.3 \\
{[0.164]}\end{array}$ & $83.5 \pm 0.3$ & $\begin{array}{c}0.07 \pm 0.01 \\
{[\sim 6]}\end{array}$ \\
\hline & $\mathrm{N}_{2}$ & $0.49 \pm 0.01$ & $\begin{array}{c}84.1 \pm 0.1 \\
{[0.159]}\end{array}$ & $83.6 \pm 0.1$ & $\begin{array}{c}0.08 \pm 0.01 \\
{[\sim 6]}\end{array}$ \\
\hline \multirow{2}{*}{ Cubic } & air & $0.80 \pm 0.09$ & $\begin{array}{l}72 \pm 1 \\
{[0.229]}\end{array}$ & $71.6 \pm 0.1 .4$ & $\begin{array}{c}0.5 \pm 0.1 \\
{[\sim 18]}\end{array}$ \\
\hline & $\mathrm{N}_{2}$ & $0.75 \pm 0.01$ & $\begin{array}{c}75.7 \pm 0.8 \\
{[0.243]}\end{array}$ & $75.3 \pm 0.8$ & $\begin{array}{c}0.58 \pm 0.05 \\
{[\sim 24]}\end{array}$ \\
\hline \multirow{2}{*}{ Kagome } & air & $0.91 \pm 0.01$ & $\begin{array}{l}68 \pm 2 \\
{[0.318]}\end{array}$ & $67.9 \pm 1.0$ & $\begin{array}{c}0.8 \pm 0.1 \\
{[\sim 21]}\end{array}$ \\
\hline & $\mathrm{N}_{2}$ & $0.82 \pm 0.03$ & $\begin{array}{l}73 \pm 1 \\
{[0.269]}\end{array}$ & $72.7 \pm 1.0$ & $\begin{array}{c}0.8 \pm 0.1 \\
{[\sim 28]}\end{array}$ \\
\hline
\end{tabular}

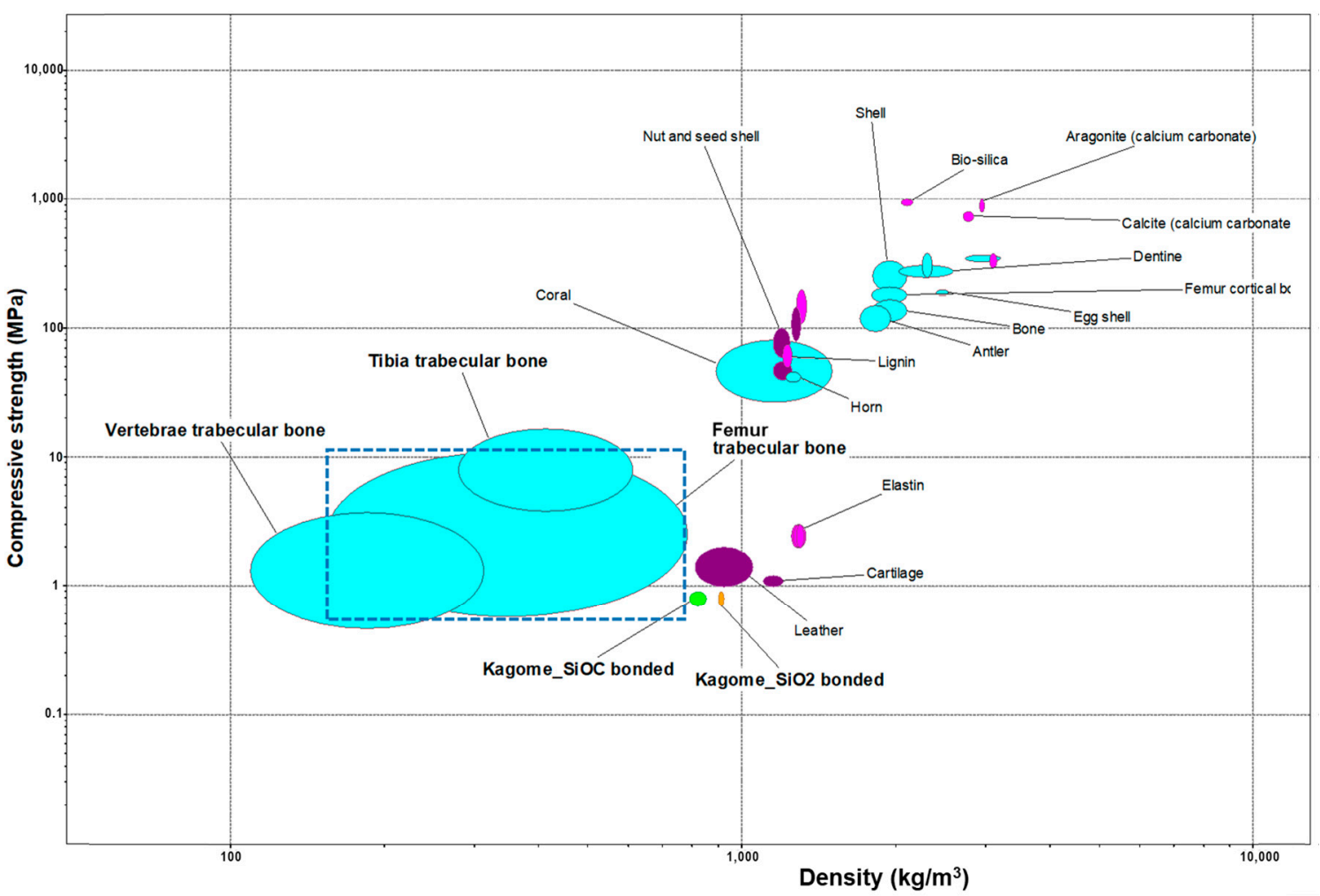

Figure 7. Ashby plot for biological materials and selected scaffolds [22].

The undoubtedly favorable effect of passing from an air to nitrogen atmosphere (increase of compressive strength from 21 to $28 \mathrm{MPa}$, for Kagome model) could be attributed to the suppression of the well-known transformation-induced cracking (upon cooling) of crystalline silica variants. The $\beta \rightarrow \alpha$-cristobalite phase transformation is the likely cause for the cracking of the silicone-derived binding phase in the samples fired in the air (as shown in Figure 5).

The packing of microbeads, after partial sintering, effectively led to highly permeable materials, as verified by infiltration of rhodamine B solution. Figure 8 confirms that the dye molecules homogeneously dispersed and easily penetrated the entire scaffolds through the channels between adjacent particles. The coloration was thus observed not only at the surface but extended also to fracture surfaces. The obtained spongy scaffolds 
could therefore be potentially beneficial for enhancing biological performance in terms of cell attachment, growth, and differentiation, as well as vascularization. Infiltration of biopolymers could be also possible to form a new class of biocomposites with enhanced mechanical properties [23].
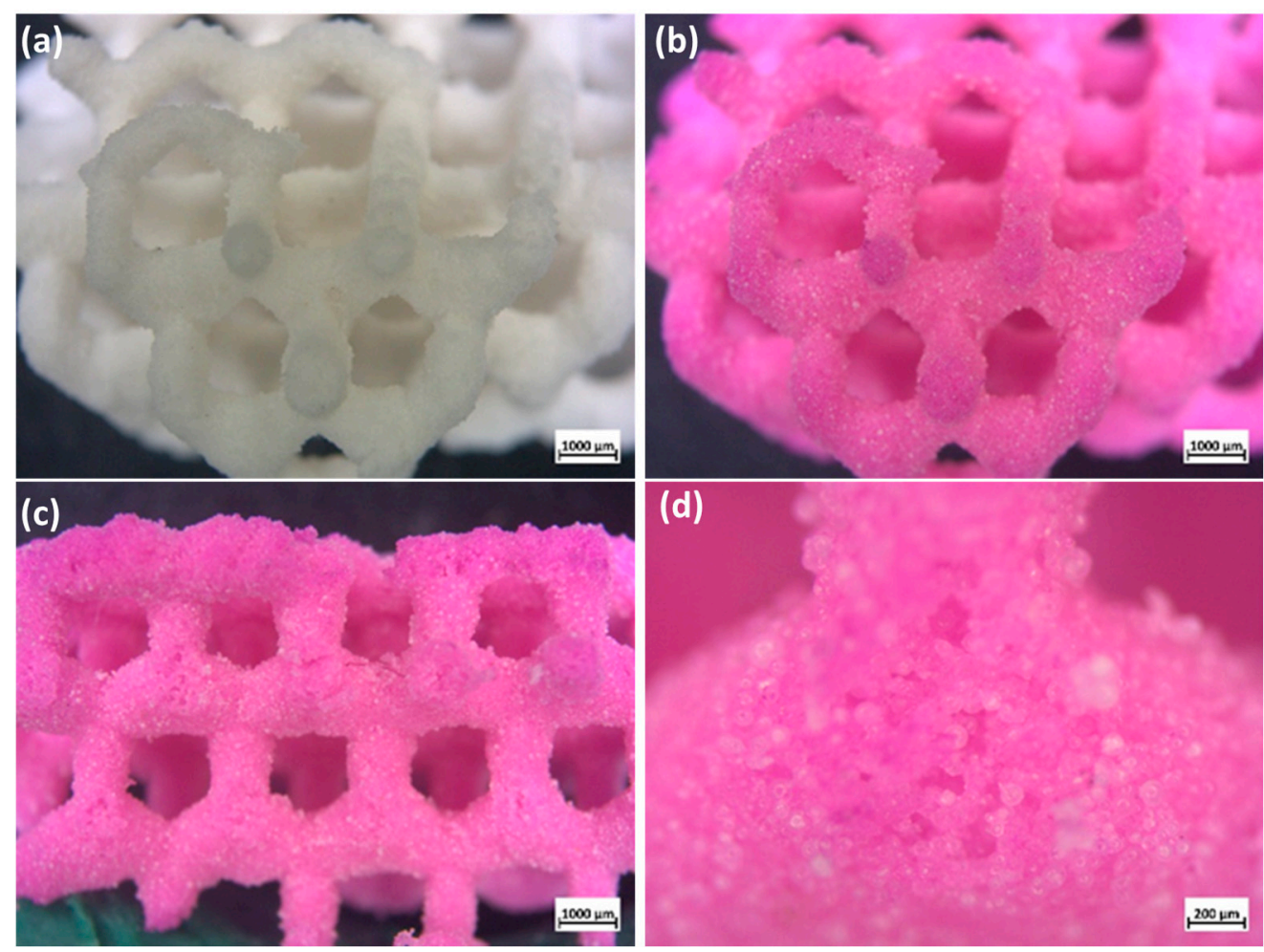

Figure 8. Optical images of (a) scaffolds (diamond lattice) fired at $1100{ }^{\circ} \mathrm{C}$ in air (before infiltration); (b) after infiltration in a Rhodamine B solution; (c,d) fracture surface (after infiltration).

To further improve the mechanical strength, additional efforts will be undertaken in terms of topological control (e.g., by adopting triply periodic minimal surface structures (gyroids), or in terms of additional inclusion of silicone resin and modifications of firing conditions). Additional surface characterization techniques (such as contact angle determinations) are envisaged. Finally, in vitro and in vivo studies will also be performed to understand the biological performance of the sintered scaffolds.

\section{Conclusions}

The åkermanite based 3D scaffolds with multiscale porosity were manufactured by stereolitography technique. The main findings are summarized as follows:

- Spherical shaped glass particles were selected to fabricate the green scaffolds. The photocurable slurry comprises photosensitive resin, $65 \mathrm{wt} \%$ glass microbeads, and $10 \mathrm{wt} \%$ silicone resin, the latter found to impart structural integrity to the scaffolds, despite poor sintering of microbeads.

- The formation of åkermanite phase was dominant at the applied sintering temperature of $1100{ }^{\circ} \mathrm{C}$. The firing conditions (firing in air or nitrogen) did not affect the crystallization of åkermanite, but affected the transformation of silicone resin into (partly crystallized) silica or fully amorphous SiOC.

- The change from silica to SiOC binding phase had a positive effect on the strength of the prepared scaffolds, by eliminating the formation of cristobalite. A more substantial effect on the compressive strength of scaffolds is associated with the adoption of different topologies. 
Author Contributions: Conceptualization, E.B. and A.D.; methodology, A.D. and E.B.; software, L.G., G.S. and A.D.; validation, A.D., E.B. and H.E.; formal analysis, A.D.; investigation, A.D.; resources, D.G., J.K., G.S. and E.B.; data curation, A.D.; writing-original draft preparation, A.D. and E.B.; writing-review and editing, A.D., D.G. and E.B.; visualization, A.D. and E.B.; supervision, J.K., D.G. and E.B.; project administration, D.G.; funding acquisition, D.G. All authors have read and agreed to the published version of the manuscript.

Funding: This paper is a part of dissemination activities of project FunGlass. This project has received funding from the European Union's Horizon 2020 research and innovation programme under grant agreement No 739566. Authors also gratefully acknowledge the financial support from Slovak Grant Agency of Ministry of Education, Science, Research and Sport, VEGA 1/0456/20.

Institutional Review Board Statement: Not applicable.

Informed Consent Statement: Not applicable.

Data Availability Statement: The data presented in this study are available on request from the corresponding author. The data are not publicly available due to privacy restrictions.

Acknowledgments: The authors are grateful to Si Chen and Ali Talimian for their experimental assistance (flame synthesis and SEM analysis). Discussions with A. R. Boccaccini (University of Erlangen-Nuremberg, Germany), scientific board member (Biomaterials) of the Centre for Functional and Surface Functionalized Glass, are greatly acknowledged.

Conflicts of Interest: The authors declare no conflict of interest.

\section{References}

1. Zhang, H.; Zhang, H.; Xiong, Y.; Dong, L.; Li, X. Development of hierarchical porous bioceramic scaffolds with controlled micro/nano surface topography for accelerating bone regeneration. Mater. Sci. Eng. C 2021, 130, 112437. [CrossRef] [PubMed]

2. Loh, Q.L.; Choong, C. Three-Dimensional Scaffolds for Tissue Engineering Applications: Role of Porosity and Pore Size. Tissue Eng. Part B Rev. 2013, 19, 485-502. [CrossRef] [PubMed]

3. Gaharwar, A.K.; Singh, I.; Khademhosseini, A. Engineered biomaterials for in situ tissue regeneration. Nat. Rev. Mater. 2020, 5, 686-705. [CrossRef]

4. Boccaccio, A.; Uva, A.E.; Fiorentino, M.; Mori, G.; Monno, G. Geometry Design Optimization of Functionally Graded Scaffolds for Bone Tissue Engineering: A Mechanobiological Approach. PLoS ONE 2016, 11, e0146935. [CrossRef] [PubMed]

5. Lu, F.; Wu, R.; Shen, M.; Xie, L.; Liu, M.; Li, Y.; Xu, S.; Wan, L.; Yang, X.; Gao, C.; et al. Rational design of bioceramic scaffolds with tuning pore geometry by stereolithography: Microstructure evaluation and mechanical evolution. J. Eur. Ceram. Soc. 2021, 41, 1672-1682. [CrossRef]

6. Gupta, D.; Singh, A.K.; Dravid, A.; Bellare, J. Multiscale Porosity in Compressible Cryogenically 3D Printed Gels for Bone Tissue Engineering. ACS Appl. Mater. Interfaces 2019, 11, 20437-20452. [CrossRef] [PubMed]

7. Dasan, A.; Elsayed, H.; Kraxner, J.; Galusek, D.; Colombo, P.; Bernardo, E. Engineering of silicone-based mixtures for the digital light processing of Åkermanite scaffolds. J. Eur. Ceram. Soc. 2020, 40, 2566-2572. [CrossRef]

8. Zadehnajar, P.; Mirmusavi, M.H.; Bakhtiari, S.S.E.; Bakhsheshi-Rad, H.R.; Karbasi, S.; RamaKrishna, S.; Berto, F. Recent advances on akermanite calcium-silicate ceramic for biomedical applications. Int. J. Appl. Ceram. Technol. 2021, 18, 1901-1920. [CrossRef]

9. Xia, L.; Yin, Z.; Mao, L.; Wang, X.; Liu, J.; Jiang, X.; Zhang, Z.; Lin, K.; Chang, J.; Fang, B. Akermanite bioceramics promote osteogenesis, angiogenesis and suppress osteoclastogenesis for osteoporotic bone regeneration. Sci. Rep. 2016, 6, 22005. [CrossRef] [PubMed]

10. Dong, X.; Li, H.; Ea, L.; Cao, J.; Guo, B. Bioceramic akermanite enhanced vascularization and osteogenic differentiation of human induced pluripotent stem cells in 3D scaffolds in vitro and vivo. RSC Adv. 2019, 9, 25462-25470. [CrossRef]

11. Huang, Y.; Wu, C.; Zhang, X.; Chang, J.; Dai, K. Regulation of immune response by bioactive ions released from silicate bioceramics for bone regeneration. Acta Biomater. 2018, 66, 81-92. [CrossRef] [PubMed]

12. Fiocco, L.; Li, S.; Stevens, M.M.; Bernardo, E.; Jones, J.R. Biocompatibility and bioactivity of porous polymer-derived Ca-Mg silicate ceramics. Acta Biomater. 2017, 50, 56-67. [CrossRef] [PubMed]

13. Dasan, A.; Talimian, A.; Kraxner, J.; Galusek, D.; Elsayed, H.; Bernardo, E. Åkermanite glass microspheres: Preparation and perspectives of sinter-crystallization. Int. J. Appl. Glass Sci. 2021, 12, 551-561. [CrossRef]

14. Elsayed, H.; Picicco, M.; Dasan, A.; Kraxner, J.; Galusek, D.; Bernardo, E. Glass powders and reactive silicone binder: Interactions and application to additive manufacturing of bioactive glass-ceramic scaffolds. Ceram. Int. 2019, 45, 13740-13746. [CrossRef]

15. Elsayed, H.; Picicco, M.; Dasan, A.; Kraxner, J.; Galusek, D.; Bernardo, E. Glass powders and reactive silicone binder: Application to digital light processing of bioactive glass-ceramic scaffolds. Ceram. Int. 2020, 46, 25299-25305. [CrossRef]

16. Sharafabadi, A.K.; Abdellahi, M.; Kazemi, A.; Khandan, A.; Ozada, N. A novel and economical route for synthesizing akermanite $\left(\mathrm{Ca}_{2} \mathrm{MgSi}_{2} \mathrm{O}_{7}\right)$ nano-bioceramic. Mater. Sci. Eng. C 2017, 71, 1072-1078. [CrossRef] [PubMed] 
17. Bernardino, R.M.; Wirth, C.; Stares, S.L.; Salmoria, G.V.; Hotza, D.; Günster, J. Manufacturing of $\mathrm{SiO}_{2}$-Coated b-TCP Structures by 3D Printing using a Preceramic Polymer as Printing Binder and Silica Source. J. Ceram. Sci. Technol. 2018, 9, 37-42. [CrossRef]

18. Fiocco, L.; Elsayed, H.; Badocco, D.; Pastore, P.; Bellucci, D.; Cannillo, V.; Detsch, R.; Boccaccini, A.R.; Bernardo, E. Direct ink writing of silica-bonded calcite scaffolds from preceramic polymers and fillers. Biofabrication 2017, 9, 025012. [CrossRef] [PubMed]

19. Elsayed, H.; Carraro, F.; Agnoli, S.; Bellucci, D.; Cannillo, V.; Ferroni, L.; Gardin, C.; Zavan, B.; Bernardo, E. Direct ink writing of silica-carbon-calcite composite scaffolds from a silicone resin and fillers. J. Eur. Ceram. Soc. 2018, 38, 5200-5207. [CrossRef]

20. Gibson, L.J.; Ashby, M.F. Cellular Solids: Structure and Properties, 2nd ed.; Cambridge University Press: Cambridge, UK, 1997.

21. Höland, W.; Beall, G.H. Glass-Ceramic Technology; John Wiley \& Sons: Hoboken, NJ, USA, 2012.

22. Ansys Granta Selector, Granta EduPack 2021 R1. https://www.ansys.com/products/materials/granta-selector/.

23. Desimone, D.; Li, W.; Roether, J.A.; Schubert, D.W.; Crovace, M.C.; Rodrigues, A.C.M.; Zanotto, E.D.; Boccaccini, A.R. Biosilicate ${ }^{\circledR}-$ gelatine bone scaffolds by the foam replica technique: Development and characterization. Sci. Technol. Adv. Mater. 2013, 14, 045008. [CrossRef] [PubMed] 